\section{P76 THE DETERMINANTS OF SUBJECTIVE WELLBEING: AN ANALYSIS OF A HEALTH AND WELLBEING SURVEY IN SOUTHEAST ENGLAND}

${ }^{1}$ AM Lagnado*, ${ }^{2} \mathrm{~K}$ Gilchrist, ${ }^{3} \mathrm{~A}$ Memon. 'Undergraduate Medical School, Brighton and Sussex Medical School, Brighton, UK; ${ }^{2}$ Directorate of Public Health, Brighton and Hove City Council, Brighton, UK; ${ }^{3}$ Epidemiology and Public Health Medicine, Brighton and Sussex Medical School, Brighton, UK

\subsection{6/jech-2017-SSMAbstracts. 177}

Background The concept of wellbeing is now increasingly used as one of the key measures of societal progress, along with the traditional methods that are based on economic activity. Subjective wellbeing (SWB) is a construct by which national wellbeing can be measured-this can inform development of health and social policy. The objective of this study was to determine the association between sociodemographic/personal factors and low subjective wellbeing.

Methods Data from the health and wellbeing survey conducted in Brighton and Hove in $2012(\mathrm{n}=2,035)$ was analysed. The survey included the Office of National Statistics verified measure of SWB, which consisted of four questions regarding life satisfaction, fulfilment, happiness and anxiety. Low SWB was the outcome measure, the threshold of which was determined according to the Faculty of Public Health outcome framework. The survey also included a range of population measures, sixteen of which were chosen as explanatory variables. The analysis included descriptive statistics and multivariate logistic regression, using the SPSS statistical programme.

Results In the multivariate analysis, poor general health (selfreported) was strongly associated with low SWB [dissatisfaction with life (adjusted OR=3.9, 95\% CI, 2.7-5.6); unfulfilled (3.4, 2.3-4.8); unhappiness $(3.0,2.1-4.2)$; anxiety $(2.4,1.7-$ 3.3)]. Other factors found to be significantly associated with low SWB included: illness and disability, low social capital, lack of physical exercise, a history of self-harm, not owning a home, not being in a relationship and being middle aged. On the other hand, unemployment, deprivation and poor education were not associated with SWB.

Conclusion This study demonstrates that an individuals SWB is likely to be affected by a number of sociodemographic/personal factors. The limitations of this study include the extent of external validity, the lack of causality and potential selection and information bias. These findings are relevant to the design and delivery of policy aimed at improving the perception of wellbeing in individuals, and the general population.

\section{P77 LEVELS OF PSYCHOLOGICAL DISTRESS AND PREDICTORS OF DISTRESS IN FAMILY CARERS OF PATIENTS WITH CANCER AT END OF LIFE}

${ }^{1} \mathrm{GE}$ Grande ${ }^{*},{ }^{1} \mathrm{C}$ Rowland, ${ }^{2} \mathrm{~B}$ van den Berg, ${ }^{3} \mathrm{E}$ Batistatou, ${ }^{4} \mathrm{~B}$ Hanratty. ${ }^{1}$ Division of Nursing, Midwifery and Social Care, University of Manchester, Manchester, UK; ${ }^{2}$ Faculty of Economics and Business, University of Groningen, Groningen, Netherlands; ${ }^{3}$ Institution of Population Health, University of Manchester, Manchester, UK; ${ }^{4}$ Institute of Health and Society, Newcastle University, Newcastle, UK

10.1136/jech-2017-SSMAbstracts. 178

Background Family carers provide substantial support for patients at end-of-life. It is important to understand how caregiving impacts on carers to guide appropriate interventions to improve carer wellbeing.
The aims of this study were to investigate levels of psychological distress and predictors of distress during end of life care giving in a national sample of family carers of people with cancer.

Methods Four-month post-bereavement postal survey of a national census sample of relatives reporting a death from cancer 1-16th May 2015. Retrospective data collected included carer demographics, carers' psychological distress (GHQ-12), care giving hours and tasks, out of pocket expenses, support from informal and formal care, other demands on carers' time (work, other caregiving responsibilities, voluntary work), opportunities for respite, patient symptoms and activities of daily living (ADL). Exploratory univariate analyses were used to describe the data and inform multivariate analysis.

Results Surveys were completed by 1504 (28.5\%) of 5271 carers. Carers' median GHQ distress score was 7 (IQR 4-9), where a score $>=4$ indicates 'caseness' for psychological distress. Univariate analysis results at $\mathrm{p}<0.05$ indicate that increased hours of caregiving, other caring responsibilities and the patient's worsening symptoms and reduced ADL increased distress. Formal support, hours of volunteering and respite were associated with reduced distress. Carer age, sex, work situation and level of deprivation also related to distress. Multivariate analysis indicates that the total hours of care giving, patients' psychological symptoms and the carer being female was related to increased distress, whilst formal service provision was related to reduced distress. The final model explained $19 \%$ of variance in distress.

Conclusion A considerable majority of family carers suffer clinically significant levels of psychological distress during end of life care giving. Objective care burden in the form of total hours of caregiving is associated with increased distress. Being female and caring for a patient with psychological symptoms appears to increase distress, whereas support from formal care services can ameliorate distress. Whilst the final model explains a modest amount of variance in carer distress, it indicates that reduction in objective care burden and support from services can have an important, positive impact.

The study was funded by Dimbleby Cancer Care; NIHR CLAHRC Greater Manchester

\section{P78 MEASURING MATERNAL MOOD}

${ }^{1}$ E Savage-McGlynn*, 'M Redshaw, ${ }^{2} \mathrm{C}$ Martin. ${ }^{1}$ National Perinatal Epidemiology Unit, University of Oxford, Oxford, UK; ${ }^{2}$ Faculty of Society and Health, Buckinghamshire New University, Uxbridge, UK

\subsection{6/jech-2017-SSMAbstracts. 179}

Background Mood disorders are common among women during the perinatal period, impacting their well-being and that of their families. Prevalence estimates range from 8 to upwards of $40 \%$. Variable detection of cases has been attributed to different measures used, timing of assessment, women not disclosing their feelings, and health professionals not asking questions in meaningful ways. Different measures have been used along the maternity care pathway, with varying reliability and specificity to detect cases and commonly employ graded multiple response format.

Listening to what women say about completing such measures, there is a clear need to develop alternative methods of assessing maternal mood in the perinatal period. 